\title{
Dentists' Perception and Clinical use of Preformed Metal Crowns to Restore Primary Molar Defects in Chengdu City, China: A Cross-Sectional Study
}

\section{Qingsong Jiang}

State Key Laboratory of Oral Diseases, West China college of Stomatology, Sichuan University

\section{Yan Wang}

State Key Laboratory of Oral Diseases, National Clinical Center for Oral Diseases, Department of

Peadiatric Dentistry, West China Hospital of Stomatology, Sichuan University

Jing Zou

State Key Laboratory of Oral Disease,National Clinical Center for Oral Disease, Department of Pediatric Dentistry, West China Hospital of Stomatology, Sichuan University

Qiong Zhang ( $\nabla$ zhangqiongdentist@126.com )

State Key Laboratory of Oral Diseases, National Clinical Center for Oral Diseases,Department of Peadiatric Dentistry, West China Hospital of Stomatology, Sichuan University https://orcid.org/00000002-5039-4648

\section{Research article}

Keywords: caries, deciduous teeth, dentist, perception, preformed metal crowns

Posted Date: October 5th, 2020

DOI: https://doi.org/10.21203/rs.3.rs-63577/v1

License: (c) (1) This work is licensed under a Creative Commons Attribution 4.0 International License. Read Full License 


\section{Abstract}

Background: Preformed metal crowns (PMCs) are recommended for the enduring restoration of primary molar defects. However, the PMC technique is not implemented in China as well as that in Western countries.

Aim: This study aimed to assess the clinical use of the PMC technique and its effective factors among dentists in Chengdu, China.

Methods: The questionnaires were distributed among 1000 dentists practicing in Chengdu via an online questionnaire platform. Data, including sociodemographic characteristics of the respondents and their perception and use of PMCs, were collected.

Results: The response rate was 45\%. Most respondents (69.6\%) did not use PMCs. Academic qualification, working specialty and working experiences were associated with dentists' use of PMCs. The lack of knowledge about PMCs technique was the main obstacle for the dental practitioners using PMCs (41.7\%). The lack of understanding of the rationale of PMCs was the main reason for parents accepting PMC restorations(43.6\%). Attending continuing education programs was the main approach to learn the PMC restorative technique(59.1\%).

Conclusion: The clinical use of PMCs was not very popular in Chengdu city. To promote the use of this restorative technique, the knowledge and practical training should be incorporated into routine courses of undergraduate dental education.

\section{Introduction}

Dental caries, a worldwide oral health burden, affects $60-90 \%$ of children and an overwhelming majority of adults in most industrialized countries. ${ }^{1}$ Early childhood caries (ECC) is an aggressive form of dental caries in preschoolers, which, left untreated, can give rise to the rapid development of extensive lesions in primary teeth, causing pain, complicated systemic infections, and financial burden. According to the report of the Fourth National Oral Health Epidemiological Survey in mainland China, the prevalence of ECC in children aged 3,4 , and 5 years was $50.8 \%, 63.6 \%$, and $71.9 \%$, respectively. However, the constituent rate of filled teeth was only $1.5 \%, 2.9 \%$, and $4.1 \%$, respectively. ${ }^{2}$

Maintenance of the primary dentition in a nonpathological condition is vital for oral health, craniofacial development, and the overall well-being of children. Therapeutic strategies of the ECC are different from those of the permanent dentition because of the specific characteristics of the anatomical morphology and histological structures of primary teeth, and even the children's psychological behavior. ${ }^{3}$ Therefore, the treatment of extensively damaged primary teeth poses a challenge for the paediatric dentists as three critical considerations have to be kept in mind: children's behavioral management, preservation of the tooth structure, and parental satisfaction. In contemporary dentistry, the defects of primary molars are mainly treated with restorative treatments, which include direct filling and full coronal restorations. ${ }^{4}$ 
Preformed metal crowns(PMCs), also known as stainless steel crowns (SSCs), are recommended for the enduring restoration for primary molars and the temporary restoration of the newly erupted first permanent molars in different occasions, including severely decayed or fractured teeth, hypoplastic or hypomineralized teeth, primary molars after pulpotomy or pulpectomy procedures, teeth with extensive wear, abutments for space maintainers, and children with a high risk of caries treated under local anesthesia. ${ }^{5}$ Compared with conventional therapeutic materials, PMCs prevent the development of caries by covering the entire dental crown surfaces and isolating the tooth structure from the oral microorganisms. Also, they exhibit greater longevity and fewer retreatment needs; thus, they constitute a preferred option for the restoration of primary molars. ${ }^{5-7} \mathrm{PMC}$ restoration is extensively accepted by dentists, children, and their parents in some developed countries, such as the UK and New Zealand. ${ }^{8,9}$ However, to the best of our knowledge, reports on dentists' perception, clinical use as well as knowledge of PMCs are considered inadequate in China.

Chengdu, located at the western edge of the Sichuan Basin, is the provincial capital of Sichuan Province. According to a cross-sectional study in Sichuan Province in 2016, the prevalence of dental caries in children aged 3-5 years was $63.55 \%$, and the mean DMFT (decayed, missing, and filled teeth) was 3.28 . The significant caries index reached 8.05, and this value was higher in urban areas than in rural areas. Relative to the high rate of decayed teeth, the prevalence of restored teeth was only $0.97 \%$ in this group. ${ }^{10}$ The prevalence of caries and health risks due to dental caries in children and adolescents in Sichuan is an essential factor not only in governmental investment and planning for dental services but in public health practitioners' and dentists' delivery and practice of dental services. Therefore, the aim of this present study was to assess the clinical use of PMCs and its effective factors in Chengdu, China.

\section{Methods}

\subsection{Study Design}

The present study was conducted on the general dental practitioners, paediatric dental specialists and other general dentists practicing in Chengdu, China, who are members of the Sichuan Society of Stomatology. The relevant questionnaire was presented to the participants via SO JUMP (https://www.wjx.cn/), an online questionnaire platform.

\subsection{Questionnaire Development}

The multi-item questionnaire (21 questions) consisted of two main sections, including single-choice and multiple-choice questions. One section dealt with the sociodemographic characteristics of the participants, including gender, age, academic qualification, working specialty, professional qualification, years of practice, nature of work units, and the number of children treated per week. The other section consisted of questions on their use and perception of PMCs, including months of applying PMCs, the charge of PMC restorations, the number of PMCs used per week, the age of young patients treated with 
PMCs, approaches to learning this technique, indications of using PMCs, and the reasons for dentists and young patients to reject PMCs.

Pilot testing was conducted on 10 dentists contacted by WeChat, a mobile text and voice messaging communication service developed by Tencent in China, to make sure it was comprehensible and acceptable to the participants. Neither the questions nor the answers were modified after the pilot study.

\subsection{Data Analysis}

The data from the questionnaire were analyzed with SPSS (Version 24, SPSS Inc., Chicago, IL, USA). Descriptive statistics were used to analyze respondents' demographic characteristics and approaches used by dentists to learn the PMC restorative technique. Logistic regression analysis was used to reveal the association between demographic characteristics and the use of PMCs. Multiple responses were used to analyze the reasons why dentists and patients rejected PMCs, as well as dentists' reported indications to use PMCs. The multivariate logistic regression model was performed with the variables with a univariate test of $P<0.05$. A $t$-test was applied to compare the mean number of children treated and the number of PMCs used by general and paediatric dentists per week, respectively. The level of significance was defined at $P<0.05$.

\section{Results}

The questionnaire return ratio was $45 \%$, with a total of 450 complete samples obtained. Table 1 shows the demographic characteristics of the studied dentists and the association with the use of PMCs. $60.2 \%$ of the respondents were female dentists. $49.3 \%$ of them were between 30 to 39 years old. $66.9 \%$ had bachelor degrees. The majority $(80.2 \%)$ of respondents were general dentists. More than half of dentists $(54.9 \%)$ were resident doctors. $183(40.7 \%)$ of them had worked for 10 to 19 years. And about half of them $(52.4 \%)$ worked in private dental clinic/hospital. 
Table 1

Demographic characteristics of the studied dentists and the association with the use of PMCs

Univariate

OR $(95 \% \mathrm{Cl})$

\section{Gender}

male

female

Age (year)

$<30$

$30-39$

$40-49$

$\geq 50$
179

(39.8)

$271 \quad 1.000$

(60.2)
Multivariate

OR $(95 \% \mathrm{Cl}) \quad P$

\begin{tabular}{llll} 
Age (year) & & & \\
\hline$<30$ & 91 & $1.156(0.376$ & 0.801 \\
& $(20.2)$ & $\sim 3.554)$ & \\
\hline $30-39$ & 222 & $1.300(0.447$ & 0.630 \\
& $(49.3)$ & $\sim 3.784)$ & \\
\hline $40-49$ & 119 & $0.876(0.288$ & 0.816 \\
& $(26.5)$ & $\sim 2.663)$ & \\
\hline 50 & 18 & 1.000 & \\
& $(4.0)$ & & \\
\end{tabular}

\section{Academic qualification}

Junior college degree and

below

71

(15.8)

$0.149(0.061$

<. $001^{* * *}$

0.094

$(0.033 \sim$

$<$

0.267 )

Bachelor degree

301

$\sim 0.367)$

0.096

(66.9) $\sim 1.080)$

0.674

(0.385

1.181)

Master degree and above

78

1.000

1.000

\section{Working specialty}

General dentist

Other dental specialist
361

(80.2)
$0.307(0.171$

$\sim 0.550$ )

$0.200(0.075$

$\sim 0.537)$
<. $001^{\star \star *}$

0.299

$(0.158 \sim$ $0.565)$

35

(7.8) $0.001^{\star \star}$

0.434

$(0.144 \sim$ 1.307)

OR: odds ratio

95\%Cl: 95\% confidence interval

${ }^{\star} P<0.05 ; * \star P<0.01 ; * \star \star * P<0.001$ 


\begin{tabular}{|c|c|c|c|c|c|}
\hline & & Univariate & & Multivariate & \\
\hline Paediatric dental specialist & $\begin{array}{l}54 \\
(12.0)\end{array}$ & 1.000 & & 1.000 & \\
\hline Professional title & & & & - & \\
\hline Resident doctor & $\begin{array}{l}247 \\
(54.9)\end{array}$ & $\begin{array}{l}0.894(0.393 \\
\sim 2.032)\end{array}$ & 0.789 & & \\
\hline Attending doctor & $\begin{array}{l}171 \\
(38.0)\end{array}$ & $\begin{array}{l}1.529(0.666 \\
\sim 3.507)\end{array}$ & 0.317 & & \\
\hline $\begin{array}{l}\text { Association senior doctor and } \\
\text { above }\end{array}$ & $\begin{array}{l}32 \\
(7.1)\end{array}$ & 1.000 & & & \\
\hline \multicolumn{6}{|l|}{ Working experiences (year) } \\
\hline $0-9$ & $\begin{array}{l}164 \\
(36.4)\end{array}$ & $\begin{array}{l}3.756(2.026 \\
\sim 6.964)\end{array}$ & $\begin{array}{l}<.001 * \star \star \\
\end{array}$ & $\begin{array}{l}3.807 \\
(1.994 \sim \\
7.271)\end{array}$ & $<.001^{\star * *}$ \\
\hline $10-19$ & $\begin{array}{l}183 \\
(40.7)\end{array}$ & $\begin{array}{l}2.276(1.224 \\
\sim 4.234)\end{array}$ & $0.009 * *$ & $\begin{array}{l}2.244 \\
(1.174 \sim \\
4.289)\end{array}$ & $0.015^{\star}$ \\
\hline$\geq 20$ & $\begin{array}{l}103 \\
(22.9)\end{array}$ & 1.000 & & 1.000 & \\
\hline \multicolumn{6}{|l|}{ Nature of working units } \\
\hline Private dental clinic/hospital & $\begin{array}{l}236 \\
(52.4)\end{array}$ & $\begin{array}{l}0.566(0.292 \\
\sim 1.097)\end{array}$ & 0.092 & $\begin{array}{l}1.242 \\
(0.577 \sim \\
2.676)\end{array}$ & 0.579 \\
\hline $\begin{array}{l}\text { Dental department in public } \\
\text { general hospital }\end{array}$ & $\begin{array}{l}171 \\
(38.0)\end{array}$ & $\begin{array}{l}0.451(0.226 \\
\sim 0.901)\end{array}$ & $0.024^{\star}$ & $\begin{array}{l}0.670 \\
(0.313 \sim \\
1.436)\end{array}$ & 0.303 \\
\hline $\begin{array}{l}\text { Public specialized dental } \\
\text { hospital }\end{array}$ & $\begin{array}{l}43 \\
(9.6)\end{array}$ & 1.000 & & 1.000 & \\
\hline \multicolumn{6}{|l|}{ OR: odds ratio } \\
\hline \multicolumn{6}{|l|}{ 95\%Cl: $95 \%$ confidence interval } \\
\hline \multicolumn{6}{|l|}{$\star P<0.05 ; * \star P<0.01 ; * \star \star P<0.001$} \\
\hline
\end{tabular}

According to the survey, most dentists $(69.6 \%)$ in Chengdu city didn't use PMCs to restore primary molar defects. Logistic regression analysis was used to analyze the association between dentists' demographic characteristics and the use of PMCs. The multivariate logistic regression model showed that junior college degree and below, general dentist and longer working years were negatively associated with the dentists' use of PMCs. 
As showed in Table 2, dentists' reluctance to use PMCs was because of a lack of knowledge to use PMCs (41.7\%), low charges/low input-output ratio (14.9\%), other technical limitations (e.g., local anesthesia) (9.3\%), a lack of compliance by children (5.6\%), aesthetic concerns (5.4\%), unawareness of PMCs (4.2\%), and other reasons (18.9\%). Parents rejected PMCs restoration because of a lack of knowledge of the merits $(43.6 \%)$, the price (24.2\%), aesthetic concerns (22.0\%), and children's non-compliance $(10.2 \%)$.

Table 2

Reasons for rejecting the use of PMCs by dentists and parents

\begin{tabular}{|c|c|c|c|c|}
\hline & & $n$ & $\begin{array}{l}\text { Percent of } \\
\text { responses(\%) }\end{array}$ & $\begin{array}{l}\text { Percent of } \\
\text { cases }(\%)\end{array}$ \\
\hline \multirow[t]{8}{*}{$\begin{array}{l}\text { Reasons for rejecting the use of } \\
\text { PMCs by dentists }\end{array}$} & $\begin{array}{l}\text { Lack of knowledge to } \\
\text { use PMCs }\end{array}$ & 210 & 41.7 & 67.1 \\
\hline & $\begin{array}{l}\text { Low charges / low } \\
\text { input-output ratio }\end{array}$ & 75 & 14.9 & 24.0 \\
\hline & $\begin{array}{l}\text { Other technical } \\
\text { limitations }\end{array}$ & 47 & 9.3 & 15.0 \\
\hline & $\begin{array}{l}\text { Non-compliance of } \\
\text { children }\end{array}$ & 28 & 5.6 & 8.9 \\
\hline & Aesthetic concerns & 27 & 5.4 & 8.6 \\
\hline & Unawareness of PMCs & 21 & 4.2 & 6.7 \\
\hline & Other reasons & 95 & 18.9 & 30.4 \\
\hline & Total & 503 & 100.0 & 160.7 \\
\hline \multirow[t]{5}{*}{$\begin{array}{l}\text { Reasons for rejecting the use of } \\
\text { PMCs by parents }\end{array}$} & $\begin{array}{l}\text { Incomprehension of } \\
\text { merits }\end{array}$ & 103 & 43.6 & 82.4 \\
\hline & Prices & 57 & 24.2 & 45.6 \\
\hline & Aesthetic concerns & 52 & 22.0 & 41.6 \\
\hline & $\begin{array}{l}\text { Non-compliance of } \\
\text { children }\end{array}$ & 24 & 10.2 & 19.2 \\
\hline & Total & 236 & 100.0 & 188.8 \\
\hline PMCs: Preformed metal crowns & & & & \\
\hline
\end{tabular}

In this study, 30 paediatric dentists and 100 general dental practitioners used the PMCs restorative technique. The mean number of children treated by paediatric dentists per week (63.70) was almost three times that by general dental practitioners $(20.56)(P<0.001)$. Accordingly, the mean number of PMCs used by paediatric dentists per week (7.73) was nearly three times that used by general dental practitioners $(2.92)(P<0.05)$ (Table 3$)$. 
Table 3

The comparison between general and paediatric dentists in terms of the number of children treated and PMCs used per week

\begin{tabular}{|llllll|}
\hline & Mean & & & \\
\hline & General dentists & Paediatric dentists & $t$ & $P$ \\
\hline Number of children treated per week & 20.56 & 63.70 & 5.615 & $<0.001 * \star \star$ \\
\hline Number of PMCs used per week & 2.92 & 7.73 & 2.736 & $0.010^{\star}$ \\
\hline PMCs: preformed metal crowns & & & & \\
\hline$* P<0.05 ; * \star \star P<0.001$ & & & & \\
\hline
\end{tabular}

Table 4

Dentists' reported main indications to use PMCs for primary molars restoration.

\begin{tabular}{|llll|}
\hline Main indications of using PMCs & $\mathbf{n}$ & $\begin{array}{l}\text { Percent of } \\
\text { responses(\%) }\end{array}$ & $\begin{array}{l}\text { Percent of } \\
\text { cases(\%) }\end{array}$ \\
\hline With multi-surfaces caries & 123 & 20.5 & 94.6 \\
\hline After endodontic treatment & 113 & 18.8 & 86.9 \\
\hline Form anomalies (e.g. enamel aplasia) & 97 & 16.2 & 74.6 \\
\hline $\begin{array}{l}\text { Dental tissues with large defects and } \\
\text { fractures }\end{array}$ & 97 & 16.2 & 74.6 \\
\hline High carious risk & 92 & 15.3 & 70.8 \\
\hline Infra-occlusion & 78 & 13.0 & 60 \\
\hline Total & 600 & 100.0 & 461.5 \\
\hline PMCs: preformed metal crowns & & & \\
\hline
\end{tabular}

This questionnaire also showed that most children who received PMCs restorations were 3-6 years of age (57.1\%). However, children younger than 3 years (8.8\%) seldom received PMCs restorations. $59.1 \%$ of the respondents gained the PMCs restorative technique through attending continuing education programs. Besides, $29.9 \%$ learned it by themselves, and only $10.9 \%$ were educated in college.

\section{Discussion}

ECC has become a worldwide disease, affecting both the oral and general health of children. PMCs have been demonstrated to be the most reliable and durable restorations for multiple lesions in primary molars, particularly for the children at high risk for caries. ${ }^{11-13}$ The PMCs restorative technique is not as popular in China as that in the US. This study investigated the use and views of the PMCs technique among general dental practitioners and paediatric dentists in Chengdu, China. 
The results showed that approximately one-third of the respondents (30.4\%) used PMCs to restore the defects in primary molars in their clinical practice, consistent with the results of previous studies in Germany and the UK. ${ }^{14,15}$ In the study conducted in Germany, general and paediatric dentists were investigated, and only $34 \%$ of the respondents routinely used the PMCs technique. Additionally, in the study conducted in the UK, $3 \%$ of the participants routinely used PMCs, with $15 \%$ infrequently, and $82 \%$ never. According to the present study, the main deterrent to the use of PMCs was a lack of knowledge of dental practitioners to place PMCs (41.7\%), consistent with the results of a previous study in Indiana. ${ }^{16}$ The results also showed that the application of PMCs was associated with the academic qualification, working specialty and working experiences of dentists. Dental practitioners with higher academic qualifications were more likely to implement the PMCs restorative technique, which might be attributed to the training of the PMCs technique in different education stages. Besides, paediatric dental specialists treated more children and used more PMCs than general dental practitioners, which was consistent with a recent study. ${ }^{17}$ This might be explained by the fact that paediatric dental specialists have a higher professional understanding of children's oral problems, treat more young patients, and are more familiar with the PMCs technique. Additionally, dentists with less working experience were more likely to use PMCs, which might be due to a higher success rate of PMCs restoration and more and more experts' recommendation in recent years. ${ }^{13,18}$ Therefore, to promote the implementation of this technique, the importance and the knowledge of the PMCs technique should be imparted during the undergraduate education, encouraging dental undergraduates to learn and practice it systematically when they participate in resident training in paediatric dentistry. For those who have not participated in this training, especially the general dental practitioners, continuing education programs could be a preferred approach. Santamaria et al ${ }^{14}$ showed that the use of PMCs was taught as a restorative procedure in $96 \%$ of German dental schools, but $27 \%$ of dental schools did not provide this practical training. The training of the PMCs restorative technique in Chinese dental schools, however, is not clear. Future studies could investigate the use and teaching of the PMCs technique in dental schools in different regions in China.

The perceived technique complexity also appeared to be associated with practitioners' reluctance to use PMCs, with $28.9 \%$ of the respondents believing that it was one of the obstacles to implementing the PMCs technique. ${ }^{14}$ In the present study, however, only $9.3 \%$ of respondents thought so. The low economic benefit was reported as the second leading limitation to the use of PMCs in the present study, with $14.9 \%$ of respondents believing that it was a reason for their reluctance to apply this technique. This issue was also analyzed in a previous study, which investigated general dental practitioners' views on using PMCs. ${ }^{15}$ In that study, some general dental practitioners believed that they would develop the use of PMCs in their daily practice if the charge could increase. On the other hand, the cost was also the second leading reason (24.2\%) for patients' hesitation to choose a PMCs restoration. In addition, non-compliance of children and the unaesthetic appearance of PMCs were other limitations for dentists to use them. ${ }^{14,19,20}$ The Hall Technique has been demonstrated to exhibit a high success rate (97\%) over five years in the UK and is regarded as one of several caries biological management options. ${ }^{21}$ It can restore carious primary molar teeth by seating a correctly sized PMCs over the tooth and sealing the carious 
lesion in, using the glass-ionomer cement. The Hall Technique could be accepted by general dental practitioners quickly given no requirement of local anesthesia, tooth preparation, or removal of the carious tissue. Moreover, BaniHani et $\mathrm{al}^{22}$ reported that the Hall Technique only cost about half of the conventional approach. Therefore, general and paediatric dentists could apply the Hall Technique to appropriate cases in their clinical practices, especially when young children accepted. However, we believe that it also poses some challenges for the dentist to select the correct size of the PMCs at first sight.

Apart from dentists' perception, the use of the PMCs technique was also affected by the views of children and their parents. The results showed that the main reason for patients' refusal was a lack of understanding of the merits of PMCs restorations (43.6\%). Therefore, dental practitioners should attach importance to explaining the rationale of the PMCs restorative technique to the parents before treatment. The dentists' attitudes and effective communication are crucial to gaining the trust and understanding of children and their guardians. ${ }^{22}$ Moreover, it is necessary to popularize children's oral health knowledge and raise public awareness of the importance of childhood dental health.

Almost all (94.6\%) dentists thought primary molars with multi-surfaces caries as the main indication for using PMCs, consistent with the results of a previous study in Germany. ${ }^{14}$ Ebrahimi et al ${ }^{23}$ showed that PMCs kept the lowest failure rates after 12 months in terms of restoration of primary molars with multisurfaces defects. Besides that, PMCs are also indicated in the following situations: primary molars after pulpectomy or pulpotomy procedures, molars with developmental defects (e.g. dentinogrnrsis imperfecta, amelogenesis inperfecta and enamel hypoplasia), teeth fracture or with extensive surface loss, high carious risk and infra-occlusion, etc. ${ }^{24}$ In clinical practice, however, not only the indications, but also dentists' experiences, the appearance, the prices, the compliance of young patients and the contraindications should be considered for the choice of PMCs restoration.

The current study showed that the majority (57.1\%) of patients who received PMCs treatment were 36 years of age, and only $8.8 \%$ of patients were younger than 3 years of age. The ECC prevalence for children aged 1,2 , and 3 years in mainland China was $0.3 \%, 17.3 \%$, and $40.2 \%$, respectively. ${ }^{25}$ PMCs restoration has a high success rate in ECC treatment ${ }^{18,26}$. However, the conventional method to place crowns is more complicated than the Hall Technique, requiring more cooperation of the young patients, ${ }^{19,21}$ which might be an obstacle preventing children under 3 years from receiving PMCs restorations. The Hall Technique is considered more comfortable for children to tolerate. ${ }^{27}$ Therefore, it should be incorporated into the routine treatments, especially for young children, who are reluctant to tolerate complicated treatments and local anesthesia. On such occasions, the dentist would be prompted to improve the ability to select the right size of PMCs immediately.

One of the limitations of the present study was the nonresponse bias. The response rate of the present study was only $45 \%$, a little bit higher than that in other studies focusing on dentists. ${ }^{14,19}$ The low response rate might partly be due to the fact that some dentists were unfamiliar with PMCs, which could 
lead to an overestimation of the rate of implementing PMCs restoration. Another limitation was the selection bias. All the participants were members of the Sichuan Society of Stomatology, who were not the optimum representatives of the whole population of dentists in China.

Overall, the present study showed that most dental practitioners did not implement the PMCs technique in Chengdu, China. The main reasons included a lack of knowledge to use PMCs, low charge/low inputoutput ratio, other technical limitations (such as local anesthesia), and children's non-compliance. Knowledge and practice of the use of PMCs should be incorporated into the routine educational curriculum of dental students during their undergraduate studies, which could enhance their understanding of this technique and encourage them to implement it to treat primary molars in their future clinical practice. Continuing education programs are also required to provide general dental practitioners with the means to learn the PMCs restorative technique. Moreover, the Hall Technique can be considered as a routine method to place PMCs, reducing the complexity of the practice, and increasing children's cooperation. Further studies should focus on the views of dental school teachers and students on the teaching of the PMCs technique.

\section{Conclusion}

Based on the results of this study, the PMCs restorative technique was used at a low rate in Chengdu, China. The main obstacles include dentists' lack of knowledge to use PMCs appropriately and patients' lack of knowledge about their merits. Dental undergraduate education and continuing education programs are responsible for promoting the use of PMCs.

\section{Abbreviations}

PMCs

Preformed metal crowns

ECC

Early childhood caries

DMFT

decayed, missing, and filled teeth

\section{Declarations}

\section{Ethics approval and consent to participate}

Ethical approval was obtained from the Research Ethics Committee of West China School of Stomatology, Sichuan University, under the code WCHSIRB-D-2019-085. A cover letter, listing the aim, scope of the questionnaire, guarantee of participant's anonymity, and the option to withdrawal from the study, was sent along with the survey. After a dentist choosing the agreed option to take part in the study, the questionnaire would display. 


\section{Consent for publication}

Not applicable.

\section{Availability of data and materials}

All data generated or analyzed during this study are included in this published article and its supplementary information files.

\section{Competing interests}

The authors declare that they have no competing interests.

\section{Funding}

This research was supported by the Applied Basic Research Project of Science and Technology Department of Sichuan Province (2020YJ0296), and the National Natural Science Foundation of China (81600864).

\section{Authors' contributions}

QZ designed the study. QJ and YW collected and analyzed the data, drafted the manuscript. JZ and QZ revised the manuscript. QZ finalized the manuscript and acts as guarantor. All authors read and approved the final manuscript.

\section{Acknowledgements}

Not applicable

\section{References}

1. Petersen PE, Bourgeois D, Ogawa H, Estupinan-Day S, Ndiaye C. The global burden of oral diseases and risks to oral health. B World Health Organ. 2005;83(9):661-9.

2. Wang X. The fourth national oral health epidemiological survey report. Beijing: People's Medical Publishing House. 2018:13-4.

3. Policy on Early Childhood Caries (ECC). Classifications, Consequences, and Preventive Strategies. Pediatr Dent. 2017;39(6):59-61.

4. Tinanoff N.Baez RJDiaz, Guillory C, et al. Early childhood caries epidemiology, aetiology, risk assessment, societal burden, management, education, and policy: Global perspective. Int J Paediatr Dent. 2019;29(3):238-48.

5. Dimitrov E, Georgieva M, Dimova-Gabrovska M, Andreeva R, Belcheva-Krivorova A. Preformed Metal Crowns as a Prosthetic Restorations in Pediatric Dentistry. J Imab. 2017;23(3):1627-32. 
6. Roberts JF, Attari N, Sherriff M. The survival of resin modified glass ionomer and stainless steel crown restorations in primary molars, placed in a specialist paediatric dental practice. Br Dent $\mathrm{J}$. 2005;198(7):427-31.

7. Randall RC, Vrijhoef MM, Wilson NH. Efficacy of preformed metal crowns vs. amalgam restorations in primary molars: a systematic review. J Am Dent Assoc. 2000;131(3):337-43.

8. Page LA, Boyd DH, Davidson SE, McKay SK, Thomson WM, Innes NP. Acceptability of the Hall Technique to parents and children. N Z Dent J. 2014;110(1):12-7.

9. Roberts A, McKay A, Albadri S. The use of Hall technique preformed metal crowns by specialist paediatric dentists in the UK. Brit Dent J. 2018;224(1):48-52.

10. Yin WYang Y-M.Chen $\mathrm{H}$, et al. Oral health status in Sichuan Province: findings from the oral health survey of Sichuan, 2015-2016. International Journal of Oral Science. 9(1):10-5.

11. Innes NP, Ricketts D, Chong LY, Keightley AJ, Lamont T, Santamaria RM. Preformed crowns for decayed primary molar teeth. Cochrane Database Syst Rev. 2015(12):CD005512.

12. Korolenkova MV, Arzumanyan AP. [Effectiveness of fillings and stainless-steel pediatric crowns for primary molars restoration: the results of prospective randomized split mouth study]. Stomatologiia (Mosk). 2019;98(3):83-6.

13. Chen K, Lei Q, Xiong H, Chen Y, Luo W, Liang Y. A 2-year clinical evaluation of stainless steel crowns and composite resin restorations in primary molars under general anaesthesia in China's Guangdong province. Br Dent J. 2018;225(1):49-52.

14. Santamaria RM, Pawlowitz L, Schmoeckel J, Alkilzy M, Splieth CH. Use of stainless steel crowns to restore primary molars in Germany: Questionnaire-based cross-sectional analysis. Int J Paediatr Dent. 2018;28(6):587-94.

15. Threlfall AG, Pilkington L, Milsom KM, Blinkhorn AS, Tickle M. General dental practitioners' views on the use of stainless steel crowns to restore primary molars. Br Dent J. 2005;199(7):453-5. discussion 41.

16. Kowolik J, Kozlowski D, Jones JE. Utilization of stainless steel crowns by general dentists and pediatric dental specialists in Indiana. J Indiana Dent Assoc. 2007;86(2):16-21.

17. Shelton A.Yepes JF.Vinson LA, et al. Utilization of Stainless Steel Crowns by Pediatric and General Dentists. Pediatr Dent. 2019;41(2):127-31.

18. Splieth CHBanerjeeABottenberg P, et al. How to Intervene in the Caries Process in Children: A Joint ORCA and EFCD Expert Delphi Consensus Statement. Caries Res. 2020:1-9.

19. Threlfall AG, Pilkington L, Milsom KM, Blinkhorn AS, Tickle M. General dental practitioners' views on the use of stainless steel crowns to restore primary molars. Brit Dent J. 2005;199(7):453-5.

20. Maggs-Rapport FL, Treasure ET, Chadwick BL. Community dental officers' use and knowledge of restorative techniques for primary molars: an audit of two Trusts in Wales. International journal of paediatric dentistry. 2000;10(2):133-9. 
21. Innes NPT.Evans DJP.Bonifacio CC, et al. The Hall Technique 10 years on: Questions and answers. Brit Dent J. 2017;222(6):478-83.

22. BaniHani A, Deery C, Toumba J, Duggal M, Effectiveness. Costs and Patient Acceptance of a Conventional and a Biological Treatment Approach for Carious Primary Teeth in Children. Caries Res. 2019;53(1):65-75.

23. Ebrahimi M, Shirazi AS, Afshari E. Success and Behavior During Atraumatic Restorative Treatment, the Hall Technique, and the Stainless Steel Crown Technique for Primary Molar Teeth. Pediatr Dent. 2020;42(3):187-92.

24. Kindelan SA, Day P, Nichol R, Willmott N, Fayle SA. British Society of Paediatric D. UK National Clinical Guidelines in Paediatric Dentistry: stainless steel preformed crowns for primary molars. Int $\mathrm{J}$ Paediatr Dent. 2008;18(Suppl 1):20-8.

25. Zhang XN.Yang SLiao ZY, et al. Prevalence and care index of early childhood caries in mainland China: evidence from epidemiological surveys during 1987-2013. Sci Rep-Uk. 2016; 6.

26. Azadani ENPengJKumar A, et al. A survival analysis of primary second molars in children treated under general anesthesia. J Am Dent Assoc. 2020;151(8):568-75.

27. Welbury RR. The Hall Technique 10 years on: its effect and influence. Brit Dent J. 2017;222(6):4212.

\section{Supplementary Files}

This is a list of supplementary files associated with this preprint. Click to download.

- supplementaryfileQuestionnaire.docx 